\section{AB0574 1 BENEFITS OF ILOPROST IN LONG - TERM STABILIZATION OR IMPROVEMENT IN NEOANGIOGENESIS IN SYSTEMIC SCLEROSIS: A 15 YEARS OBSERVATION COHORT}

P. Faggioli ${ }^{1}$, L. Castelnovo ${ }^{2}$, A. Tamburello ${ }^{1}$, A. Laria ${ }^{2}$, A. M. Lurati ${ }^{2}$, A. Mazzone ${ }^{1} .{ }^{1}$ Ospedale di Legnano, Medicina Interna, Legnano, Italy; ${ }^{2}$ Hospital Giuseppe Fornaroli, Reumatologia, Magenta, Italy

Background: In Systemic Sclerosis (SSc) fibrosis is due to microcirculation damage with capillary necrosis, arteriolar intimal proliferation and local ischemia. loprost (ILO) is used IV for the treatment of severe Raynaud phenomenon (RP) and digital ulcers (DU) in (SSc). We have already described (1) an improvement of peripheral vascularization with ILO, observed after 3 years treatment by capillaroscopy with an increase in the capillary number and mild regression of avascular areas and pericapillar oedema

Objectives: Our aim was to observe capillaroscopic changes in a cohort of 26 patients treated with ILO, once a month (25 - 50ng each infusion) for an average time of 15 years

Methods: We evaluated the initial and 2019 capillaroscopic picture of 26 SSc patients $(24 \mathrm{~W}, 2 \mathrm{M}$; median age $63.8 \mathrm{Y})$ in continuous treatment with monthly infusion of ILO from 2004 to today. 6/26 were SCL70 positive;the remainder was positive for anticentromere $\mathrm{Ab}$

Results: We documented stability of capillaroscopic picture in $62 \%$ of patients,an improvement in $19 \%$ and a worsening (mainly from early to active pattern) in $19 \%$. Low adherence to therapy was observed among the worsened patients. Out of 8 patients with onset ulcers, only 3 patients still have skin ulcers, all with late stable capillaroscopic picture from onset.We have not documented serious adverse events

Conclusion: Our observations confirm the efficacy and safety of ILO in the treatment of SSc even after many years of treatment, resulting in a stabilization of microvascular damage, independent of disease severity.

References:

[1] Possible role of iloprost (stable analog of PG12) in promoting neoangiogenesis in systemic sclerosis. Faggioli P, Giani L, Mazzone A. Clin Exp Rheumatol. 2006 Mar-Apr;24(2):220-1. No abstract available

Disclosure of Interests: None declared

DOI: 10.1136/annrheumdis-2020-eular.2869

\section{AB0575 THE ROLE OF LONG-TERM AND INTENSIVE IV ILOPROST TREATMENT IN REDUCTION OF PULMONARY ARTERY PRESSURE AND PRO-BRAIN NATRIURETIC PEPTIDE (PBNP) IN SCLERODERMA PATIENTS}

R. Foti ${ }^{1}$, E. Visalli ${ }^{1}$, G. Amato ${ }^{1}$, A. Benenati ${ }^{1}$, S. Bellofiore ${ }^{2}$, M. Mule ${ }^{3}$, M. DI Gangi'. ' AOU Policlinico Vittorio Emanuele, Rheumatology Unit, Catania, Italy; ${ }^{2}$ AOU Policlinico Vittorio Emanuele, Division of General Thoracic Surgery, Catania, Italy; ${ }^{3} \mathrm{AOU}$ Policlinico Vittorio Emanuele, Division of Cardiology, Catania, Italy

Background: Systemic sclerosis (SSc) is a chronic immune-mediated connective tissue disease with heterogeneous organ involvement that reduces the life expectancy of this patients. In particular cardiopulmonary manifestations, such as pulmonary arterial hypertension (PAH), are currently the primary cause of death and stabilizing this condiction may represent an important therapeutic goal $(1,2)$. An increased NT-proBNP is predictors of PAH in SSc and use this markers should result in improved PAH risk stratification (3)Some studies have suggested the role of intravenous iloprost in preventing the incidence of most severe vascular complications in long term treated patients (4)

Objectives: The aim of our study is to evaluate the evolution of the disease, with particular focus on cardiopulmonary function, in a group of consecutive patients chronically treated with iloprost at the Rheumatology Unit of Catania Hospital, Italy, from 2006 to 2019.

Methods: 68 SSc patients (58F, $52.88 \pm 12.6$ years). At baseline, $67.6 \%, 25 \%$ and $5.9 \%$ had a limited, diffuse and early scleroderma type respectively and $20,6 \%$ had interstitial lung disease. The follow-up period of the study was of 9.9 \pm 2.9 years. Iloprost was administered with a regimen of 6 infusions per month $(6$ hours $/$ day, $0.5-2.0 \mathrm{ng} / \mathrm{kg} / \mathrm{min}$ ) to treat secondary Raynaud's phenomenon (RP), diagnosed at an average age of $46.6 \pm 13.7$ years. We evaluated: skin score (SS), systolic pulmonary arterial pressure (PAPs), plane tricuspid annular systolic excursion (TAPSE), lung diffusing capacity of carbon monoxide (DLCO), forced vital capacity (FVC), alveolar volume (VA), DLCO/VA, pro-brain natriuretic peptide (pBNP), and NYHA class. We analyzed the patients as a whole group (68 subjects), as a group who continued the treatment ( 57 subjects) and as a group who stopped the treatment during the follow-up (11 patients).
Results: After the long follow up period in the study (almost 10 years) in the whole group of patients, PAPs and pBNP showed statistically significant improvement from baseline $(30.91 \pm 6.4$ vs $27.36 \pm 7.1$ and $97.20 \pm 69.3$ vs $66.65 \pm 44.3$ respectively, $p<0.0001$ for both) while the other parameters showed no significant changes: SS $(4.70 \pm 5.3$ vs $3.86 \pm 4.2 \mathrm{~mm})$, TAPSE $(22.07 \pm 2.4$ vs $22.06 \pm$ $3.8 \mathrm{~mm}), \mathrm{DLCO}(83.68 \pm 13.5 \mathrm{vs} 77.70 \pm 14.6 \mathrm{mmol} / \mathrm{kPa} \cdot \mathrm{min}), \mathrm{FVC}(107.09 \pm 14.5$ vs $107.72 \pm 18.7$ liters), VA (91.12 \pm 13 vs $90.30 \pm 14.4$ liters), DLCO/VA ( $88.48 \pm$ 13.5 vs $89.5 \pm 16.3)$ and NYHA class $(1.0 \pm 0.0$ vs $1.0 \pm 0.0)$. A subgroup analysis indicated a significant improvement in addition to PAPs and pBNP also for skin score for 57 patients who continued the treatment $(5.09 \pm 5.7$ vs $3.30 \pm 4.2, p<$ $0.0001)$ and a significant worsening of this parameter as early as the first year of suspension ( $p<0.05$ year $1, p<0.01$ year 2 and 3 ) in 11 patients who stopped the treatment

Conclusion: Cardiac involvement is recognised as a poor prognostic factor among systemic sclerosis (SSc) patients, significantly to mortality and $\mathrm{N}$-TproBNP peptide may represent a surrogate marker for cardiac involvement in SSc, selectively identifying patients with severe impairment of cardiac function Our intensive (6 infusions/month) and chronic regimen of iv iloprost administration seems improve the long-term evolution of disease in SSc patients, as sug gested by the improvement of cardiopulmonary parameters and the significant improvement of SS.

\section{References:}

[1] Rheumatology 51, 1027-36 2) Best Pract Res Clin Rheumatol.32, 223-240 3 ) Arthritis Rheum. 2008 58, 284-9 4) Rheumatol Int 2012;32:1933-8.

Disclosure of Interests: Rosario Foti Consultant of: lilly, sanofi, MSD, Janssen, Abbvie, BMS, celgene, roche, Speakers bureau: lilly, sanofi, MSD, Janssen, Abbvie, BMS, celgene, roche, elisa visalli Consultant of: lilly, sanofi, MSD, Janssen, Abbvie, BMS, celgene, roche, Speakers bureau: lilly, sanofi, MSD, Janssen, Abbvie, BMS, celgene, roche, Giorgio Amato: None declared, Alessia Benenati: None declared, Salvatore Bellofiore: None declared, Massimiliano Mule': None declared, Marcella Di Gangi: None declared DOI: 10.1136/annrheumdis-2020-eular.5178

\section{AB0576 INCIDENCE AND CLINICAL MANIFESTATIONS OF RAYNAUD'S PHENOMENON IN RHEUMATIC DISEASES}

I. Gaisin ${ }^{1}$, Z. Bagautdinova ${ }^{2}$, R. Valeeva ${ }^{1}$, N. Maximov ${ }^{1}$, O. Desinova ${ }^{3}$, R. Shayakhmetova ${ }^{3}$, I. Sabelnikova ${ }^{2}$, A. Tukmacheva ${ }^{2}$, L. Gibadullina ${ }^{2}$ N. Burlaeva ${ }^{2}$, E. Agareva ${ }^{2}$,Y. Ochkurova ${ }^{2}$, T. Bragina ${ }^{2}$, K. Alexandrova ${ }^{2}$, E. Reutova ${ }^{2}{ }^{1}$ Izhevsk State Medical Academy, Izhevsk, Russian Federation ${ }^{2}$ Clinical Diagnostic Centre of the Udmurt Republic, Izhevsk, Russian Federation; ${ }^{3}$ VA. Nasonova Research Institute of Rheumatology, Moscow, Russian Federation

Background: Systemic sclerosis (SSc) is a connective tissue disease (CTD) most frequently associated with Raynaud's phenomenon - RP (96\%), followed by mixed CTD (MCTD) (86\%), systemic lupus erythematosus - SLE $(31 \%)$, undifferentiated CTD (30\%), rheumatoid arthritis - RA (22\%) and Sjogren's disease - SD $(13 \%)^{1}$. RP can manifest as a classical triple-colour change with pallor (ischaemic phase) followed by cyanosis (deoxygenation) and erythema (reperfusion $)^{2,1}$. However, this triple-colour change only occurs in $19 \%$ of cases ${ }^{2,3}$ Majority of patients report an episodic double-colour change, consisting of pallor and cyanosis, pallor and erythema or cyanosis and erythema ${ }^{2}$. In a 4.8-year follow-up, $37.2 \%$ of RP patients developed rheumatic diseases (RD), $8.1 \%$ had other causes, in $54,7 \%$ RP remained primary ${ }^{4}$.

Objectives: To study the incidence and manifestations of secondary RP in RD. Methods: A questionnaire survey conducted in 230 patients with RD.

Results: RP was detected in $45.6 \%$ of RD patients ( $n=105), 54.4 \%$ of patients with RD had no RP ( $n=125)$. RP was 4 times more frequent in females than in males (F:M 4:1). In RP group, 87 patients (82\%) had autoimmune RD: SSc $(55.2 \%)$, SLE $(17.1 \%)$, RA $(6 \%)$, dermatomyositis $(3.8 \%)$, cross syndrome $(3.8 \%)$, MCTD $(1.9 \%)$, SD $(0.9 \%)$

Only $84 \%$ of RP patients had positive answers to all three questions that characterize RP (1. Is there an unusual sensitivity of fingers to cold? 2. Do fingers change color when exposed to cold? 3. Do they turn white and/or bluish?). Biphasic color changes (whitening-blueness; whitening-redness; blue-redness) were observed in $33(31.4 \%)$ patients with RP, three-phase changes - in 32 patients $(30.5 \%)$. Blueness of fingers to cold was more frequent in SLE than in SSc $(p=0.027)$. Redness of fingers to cold occurred more often in cross syndrome, MCTD, SD, RA, vasculitis than in SSc $(p<0.001)$ and in vasculitis than in SLE $(p=0.035)$. In SSc patients, whitening of fingers to cold was more common than redness $(p=0.037)$ and two-/three-phase changes of fingers color in the cold were more frequent than single-phase changes $(p<0.001)$ 